\title{
Article
}

\section{Sexual Aggression in Sport}

Carter, Daniel, Mark, Khan, Roxanne and Brewer, Gayle

Available at http://clok.uclan.ac.uk/21274/

Carter, Daniel, Mark, Khan, Roxanne ORCID: 0000-0002-3485-2450 and

Brewer, Gayle (2018) Sexual Aggression in Sport. Journal of Forensic Practice, 20 (3). pp. 211-214. ISSN 2050-8794

It is advisable to refer to the publisher's version if you intend to cite from the work. http://dx.doi.org/10.1108/JFP-10-2017-0042

For more information about UCLan's research in this area go to http://www.uclan.ac.uk/researchgroups/ and search for < name of research Group>.

For information about Research generally at UCLan please go to http://www.uclan.ac.uk/research/

All outputs in CLoK are protected by Intellectual Property Rights law, including Copyright law. Copyright, IPR and Moral Rights for the works on this site are retained by the individual authors and/or other copyright owners. Terms and conditions for use of this material are defined in the policies page.

\section{CLoK}

Central Lancashire online Knowledge www.clok.uclan.ac.uk

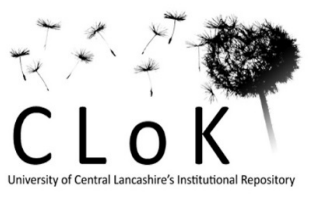




\section{Sexual Aggression in Sport}

\begin{tabular}{|r|l|}
\hline Journal: & Journal of Forensic Practice \\
\hline Manuscript ID & JFP-10-2017-0042.R2 \\
\hline Manuscript Type: & Brief literature/discussion Paper \\
\hline Keywords: & $\begin{array}{l}\text { Intervention, Sexual aggression, Sexual coercion, Sexual violence, Sport, } \\
\text { Prevention methods, Coaching }\end{array}$ \\
\hline \multicolumn{2}{|l}{} \\
\hline
\end{tabular}

SCHOLARONE ${ }^{\mathrm{m}}$

Manuscripts 
1

2

3

4

5

6

7

8

9

10

11

12

13

14

15

16

17

18

19

20

21

22

23

24

25

26

27

28

29

30

31

32

33

34

35

36

37

38

39

40

41

42

43

44

45

46

47

48

49

50

51

52

53

54

55

56

57

58

59

60

Sexual Aggression in Sport 


\begin{abstract}
Purpose: The purpose of this paper is to provide an overview of the sexual aggression in sport literature, including an analysis of interventions delivered to athletes that focus on the role of the coach and wider sporting community. The paper will also discuss the limitations of applying such prevention methods and possible directions for future research.
\end{abstract}

Approach: This paper provides an overview of research investigating the prevalence of sexually aggressive behaviour perpetrated by athletes, theoretical explanations of their sexual misconduct, and the application of violence prevention methods delivered to athletes.

Findings: Research findings are discussed in relation to the prevalence of sexual aggression in sport and the efficacy of prevention methods.

Originality/value: This is a viewpoint piece.

Keywords: Intervention, Sexual aggression, Sexual coercion, Sexual violence, Sport, Prevention methods, Coaching.

Paper type: Viewpoint. 
As the physical and psychological health benefits of sporting activity are wellestablished, engagement in sport is often encouraged. Concerns have been raised, however, with regard to athletes' off-field conduct and their use of sexually aggressive behaviour in particular. This paper will discuss the prevalence of sexually aggressive behaviour by athletes, and prevention methods that focus on the role of the coach and the wider sporting community. Limitations of existing research will be identified along with directions for future research. For the purposes of this article, sexual aggression is defined as "any sexual act, attempt to obtain a sexual act, unwanted sexual comments or advances, or acts to traffic, or otherwise directed, against a person's sexuality using coercion, by any person regardless of their relationship to the victim, in any setting, including but not limited to home and work" (Krug, Dahlberg, Mercy, Zwi, \& Lozano, 2002, p149).

Research studies consistently document a higher prevalence of sexually aggressive attitudes and behaviour amongst athletes compared to non-athletes. However, much of the research is conducted in North American student populations. These findings have been reported in self-report studies with female victims and male perpetrators (e.g., Frintner \& Rubinson, 1993). Furthermore, records indicate that in student populations, athletes are significantly more likely to be reported to judicial affairs for sexual assault than non-sporting male students (Crosset, Ptacek, McDonald, \& Benedict, 1996).

Research suggests that aggression towards women varies between sports, in particular, team sports that reflect male hegemony may encourage physical and sexual aggression towards women (Benedict, 1997). Athletes that play aggressive sports are significantly more likely to engage in dating aggression and sexually coercive behaviour than non-aggressive sporting or non-sporting participants (Forbes, Adams-Curtis, Pakalka, \& White, 2006). In particular, it has been reported that players of sports such as American football and basketball display higher levels of aggression and are more likely to hold sexist 
attitudes compared with players of other sports and are more likely to abuse their partners (McCauley et al. 2014). It is unclear, however, whether sexual aggression associated with these sports reflects the nature of the sport itself or the status afforded to such sports in popular culture.

It has been proposed that five main factors contribute to greater incidence of sexual aggression amongst student athletes. These factors are 1) male bonding, 2) sport acting as a masculine proving ground, 3) combative sports and violence, 4) the athletic justice system, and 5) 'big man on campus' syndrome (Melnick, 1992). Such research suggests that athletes may wish to prove themselves to their peers or develop a sense of grandeur from being part of the team. Alternatively, the violent aspect of combative sports may influence off-field behaviour and the protection afforded to players by the justice system may facilitate sexually aggressive behaviour.

Social norms within teams can influence the likelihood of sexual aggression. For example, peer groups may hold negative attitudes towards women (e.g., as objects of sexual conquest) that promote violence and implicitly or explicitly support sexually aggressive and coercive behaviour. Furthermore, engagement in sport is often associated with increased rates of hazardous drinking through socialising and team bonding and consumption of alcohol appears to contribute to incidence of sexual aggression. Such findings may indicate that the Confluence Model of Sexual Aggression may assist explanations of sexual aggression in sport. Although limited research has been conducted in this domain inferences can be made in relation to both paths of sexual aggression proposed by the Confluence Model from a sporting context. Inferences can be made on the grounds that the Hostile Masculinity path can relate to negative attitudes held by athletes towards women and the Promiscuous-Impersonal Sex path can relate to the socialising and team bonding aspect of sport (Malamuth, Linz, Heavey, Barnes, \& Acker, 1995). 
A range of interventions have been developed to prevent sexual aggression (e.g., addressing social norms that facilitate negative attitudes towards women) or rehabilitate perpetrators. As the target population and context may influence the design of the intervention or intervention success, this paper focuses on prevention methods that can be administered to sports teams with relative ease and limited disruption to the team. Sports coaches and senior team members appear particularly well-placed to facilitate interventions as they maintain frequent contact with their athletes and in some cases interact with athletes on a daily basis. Such interactions can take place during training sessions, competitions, or even outside of sport. Interactions between the coach, senior team members, and athletes provide opportunities for trust and close relationships to develop. In addition, they can be regarded as authority figures and have the potential to be seen as role models by athletes. Indeed research suggests that coach expectations about off-field conduct influence the likelihood that athletes will intervene to prevent inappropriate sexual behaviour (Kroshus, Paskus, \& Bell, 2015).

The community approach to the prevention of sexual violence avoids labelling men as potential perpetrators and women as potential victims and instead asserts that everyone has a role to play in ending sexual violence (Moynihan \& Banyard, 2008). This approach focuses on the role of bystanders who may be in a position to intervene before, during, and after an incident occurs. Bystanders are encouraged to behave in a pro-social manner and are taught how to safely intervene in situations involving sexual violence. Such interventions could include taking action and interrupting prior to or during to a sexually violent incident or challenging social norms that promote sexual violence. Furthermore, bystanders are taught skills to enable them to act effectively as a supportive ally to survivors of sexual assault.

Bystander intervention is based on the principle that community norms such as those found in sports teams can facilitate pro-sexually aggressive attitudes and behaviour. The 
focus is therefore placed on the role of bystanders to act pro-socially; specifically by acting as a deterrent to sexual aggression and supporting survivors. Moynihan and Banyard (2008) conducted a trial bystander intervention programme. The study involved participants from two intercollegiate sports teams (21 men and 18 women), one fraternity (42 men), and one sorority (46 women). Peer group leaders received six hours of training on bystander intervention and all participants completed a pre-test survey prior to the commencement of the programme. The intervention consisted of a 90-minute session delivered by practitioners and peer group leaders, delivered to each participant group separately. Results indicated that the bystander intervention program had a positive impact on both men and women from pretest to post-test.

Coaching Boys into Men is a social norms based programme delivered by athletic coaches. The programme aims to reduce sexual violence by promoting bystander intervention and altering gender norms that impact on negative attitudes and behaviour towards women. A series of twelve sessions are delivered at weekly intervals throughout the athletic season. The sessions focus on respect, sexual consent, non-violence, and intervening when witnessing abusive behaviour perpetrated by peers. Coaches serve as role models and clearly communicate their expectations with regard to athletes' off-field behaviour (see, www.coachescorner.org).

Jaime and colleagues (2015) conducted a mixed methods evaluation of the impact of Coaching Boys into Men. Coaches in the intervention group were provided with training and a 'coach's kit' containing the resources for delivering the program. The control group received no training and continued with their usual coaching methods. The researchers reported that intervention coaches witnessed more abusive behaviour than control coaches, suggesting that the intervention delivery increased the coaches' ability to identify abusive behaviour perpetrated by their athletes. Furthermore intervention coaches were more 
confident addressing the abusive behaviour of their athletes and reported a greater number of sexual violence discussions with their athletes. Findings suggest that if the coach is equipped to identify and deal with sexually aggressive behaviour, they can play a key role in reducing violence perpetrated by their athletes.

Research investigating sexual aggression is, however, limited by a reliance on selfreport measures, which can be subject to social desirability bias even when participant anonymity is preserved. Furthermore attitudes towards sexual aggression may not appropriately reflect perpetration of such behaviour. The majority of research conducted in this area has recruited student samples from large North American universities and it is important to establish the extent to which these issues also impact on non-student populations from other cultures and those engaged in sport at a range of levels. Indeed greater integration of the sport and offender literature is recommended. It is also important to acknowledge that such research is predominantly focused on male perpetrators towards female victims. However, there is research that highlights a high prevalence of sexual abuse reported by both male and female athletes $(21 \%$ and $31 \%$ respectively) in a sporting environment (Leahy, Pretty, \& Tenenbaum, 2002). Of course, the most important limitation of research conducted in this area is arguably the failure to establish whether sport encourages athletes to become sexually aggressive or if aggressive individuals are more likely join sports teams. Researchers have suggested both that individual differences may encourage participation in specific sports and that physical activity contributes to personality change.

Research demonstrates that sports teams are not a homogenous group and there are important differences between sports and even differences within sports (e.g., between offensive and defensive players). Therefore, future research should consider a range of factors influencing sexual aggression perpetrated by athletes, including the sporting environment, specific subcultures, and the personality traits of those who participate in sport. 
Such research will allow intervention methods to be tailored to suit the varying nature of athletes across different sporting contexts.

In conclusion, research indicates that engagement in sport is associated with sexually aggressive attitudes and behaviour. However, as evidence demonstrates that sports teams are not a homogenous group, further research is required to identify those sports that are more prone to sexually aggressive behaviour and how it is facilitated within the respective teams. While it is important to state that the responsibility of perpetrating sexually aggressive acts lies solely with the perpetrator, there is potential to reduce the perpetration of such acts using programmes such as Coaching Boys into Men and bystander intervention. Avoiding labelling men as perpetrators and women as victims may enable those participating in intervention programs to positively adopt a role in preventing sexual aggression. The delivery method of such programmes also shows promise as the interventions are delivered by peer group leaders or coaches that are already respected by those participating in the programme.

\section{Implications for Practice}

- The article identifies limitations of previous research. Such limitations include a range of methodological issues but most importantly the failure to establish whether sport encourages athletes to be more sexually aggressive or if those individuals are drawn to sport.

- Intervention methods are analysed that may be particularly effective if delivered in a sporting domain.

- Future directions of research are suggested that may enable interventions to be tailored to suit the varying nature of athletes across different sporting contexts.

\section{References}


Benedict, J.R. (1997). Public heroes private felons: Athletes and crimes against women. Boston: Northeastern University Press.

Crosset, T.W., Ptacek, J., McDonald, M.A., \& Benedict, J.R. (1996). Male student-athletes and violence against women: A survey of campus judicial affairs offices. Violence Against Women, 2, 163-179.

Forbes, G.B., Adams-Curtis, L.E., Pakalka, A.H., \& White, K.B. (2006). Among college men as a function of participation in aggressive high school sports. Violence Against Women, 12, 441-455.

Frintner, M.P., \& Rubinson, L. (1993). Acquaintance rape: The influence of alcohol, fraternity membership, and sports team membership. Journal of Sex Education and Therapy, 19, 272-284.

Jaime, M.C.D., McCauley, H.L., Tancredi, D.J., Nettiksimmons, J., Decker, M.R., Silverman, J.G., \& Miller, E. (2015). Athletic coaches as violence prevention advocates. Journal of Interpersonal Violence, 30, 1090-1111.

Kroshus, E., Paskus, T., \& Bell, L. (2015). Coach expectations about off-field conduct and bystander intervention by U.S. college football players to prevent inappropriate sexual behavior. Journal of Interpersonal Violence, 1-23.

Krug, E.G., Dahlberg, L.L., Mercy, J.A., Zwi, A.B., \& Lozano, R. (2002). World report on violence and health. Geneva: World Health Organization.

Leahy, T., Pretty, G., \& Tenenbaum, G. (2002). Prevalence of sexual abuse in organized competitive sport in Australia. The Journal of Sexual Aggression, 8, 16-36. 
Malamuth, N. M., Linz, D., Heavey, C. L., Barnes, G., \& Acker, M. (1995) Using the Confluence Model of Sexual Aggression to predict men's conflict with women: A 10year follow-up study. Journal of Personality and Social Psychology, 69, 353-369.

McCauley, H.L., Jaime, M.C.D., Tancredi, D.J., Silverman, J.G., Decker, M.R., Austin, S.B., Jones, K., \& Miller, E. (2014). Differences in adolescent relationship abuse perpetration and gender-inequitable attitudes by sport among male high school athletes. Journal of Adolescent Health, 54, 742-744.

Melnick, M. (1992). Male athletes and sexual assault. Journal of Physical Education, Recreation \& Dance, 63, 32-36.

Moynihan, M.M., \& Banyard, V.L. (2008). Community responsibility for preventing sexual violence: A pilot study with campus Greeks and intercollegiate athletes. Journal of Prevention \& Intervention in the Community, 36, 23-38. 